\title{
Effect of the degree of acetylation, plasticizer concentration and relative humidity on cassava starch films properties
}

\author{
Vivian Consuelo Reolon SCHMIDT ${ }^{1 *}$, Nuria BLANCO-PASCUAL², Giustino TRIBUZI²; João Borges LAURINDO²
}

\begin{abstract}
The objective of this study was to develop films with reduced hygroscopicity and improved mechanical properties from acetylated cassava starch. For that, an acetylation procedure using acetic anhydride as the esterification reagent was performed, resulting in starch acetates with degrees of substitution (DS) of 0.6 (S0.6) and 1.1 (S1.1). Twelve films formulations were studied: native cassava starch (S), starch acetate S0.6 and S1.1, with two glycerol concentrations (0.25 g.100 g-1 (25) and $\left.0.30 \mathrm{~g} .100 \mathrm{~g}^{-1}(30)\right)$. The films were conditioned at the relative humidities $(\mathrm{RH})$ of $58 \%$ and $75 \%$ for $96 \mathrm{~h}$ before characterization. Water vapor permeability, water solubility, water sorption isotherms, microstructural analyses, and mechanical properties in different relative humidity and different glycerol concentration were performed. Starch acetate films (S1.1) resulted in lower water vapor permeability $\left(2.35 \pm 0.26 \times 10^{-7} \mathrm{~g} / \mathrm{m} . \mathrm{s} . P a\right)$ and water solubility $\left(21.2 \pm 0.16 \mathrm{~g} .100 \mathrm{~g}^{-1}\right)$ than native starch films $\left(3.79 \pm 0.26 \times 10^{-7} \mathrm{~g} / \mathrm{m} . s . P a\right.$ and $\left.25.46 \pm 0.12 \mathrm{~g} .100 \mathrm{~g}^{-1}\right)$. S0.6 films showed higher tensile strength $(8.42 \pm 0.84 \mathrm{MPa})$ than S1.1 films $(6.93 \pm 0.55 \mathrm{MPa})$. The results indicated that acetylated starch can be used to produce films with improved mechanical properties, with less water solubility and permeability to water vapor, especially when starch acetate with 0.6 DS and low glycerol concentration are used. Chemical compounds used in this article: Starch, acetate (PubChem CID: 24832118); Acetic acid (PubChem CID: 176); Acetic anhydride (PubChem CID: 7918); Sulfuric acid (PubChem CID: 1118); Glycerol (PubChem CID: 753).
\end{abstract}

Keywords: films; starch acetate; biodegradable; physical properties.

Practical Application: There are studies on acetylated starch in the literature. These studies present chemical and physical-chemical analysis with different degree of acetylation. In context, these studies show that the starch is less soluble in water with different degree of acetylation. And some factors influence this chemical modification, as the original source of starch and esterification reagent. The originality of this paper was esterified starch cassava, producing starch acetate with different degrees of acetylation and use it in the preparation of biodegradable films, analyzing their mechanical, structural and hygroscopic properties.

\section{Introdution}

Difficulties to produce waterproof starch based films are widely reported in literature (Golachowski et al., 2015). Starch hydrophilic nature limits its use and new products development (Mbougueng et al., 2012; Raina et al., 2007). Modifications of native starch can be performed to enhance its positive attributes and to reduce shortcomings (Ashogbon \& Akintayo, 2014). Starch acetates with high degree of substitution (DS $>1$ ) have been studied for $60 \mathrm{y}$ with the aim of replacing cellulose acetate (Chi et al., 2008).

Chemical modifications and the incorporation of hydrophobic materials in the starch matrix can improve the mechanical properties, reduce hydrophilicity and give active properties to starch-based films, enabling its use as packaging material. Several authors have reported the use of chemically modified starches to obtain new materials, e.g. pre gelatinized, acid modified and acetylated starches (Golachowski et al., 2015; Mbougueng et al., 2012; Bartz et al., 2012). In particular, acetylated starch is a starch ester that has been widely studied over the last two decades (Chi et al., 2008).
Esterification of starch involves the introduction of functional groups into the starch molecules, resulting in markedly altered physicochemical properties (Bartz et al., 2012). The introduction of side chains or amylose ester radicals is commonly expressed as the degree of substitution (DS). Depending on the nature of the substituent and the degree of substitution, starch properties can be widely modified (Ashogbon \& Akintayo, 2014; Huang et al., 2007). The DS influences the water solubility of starch acetate films, i.e. i) DS below 1.1 are soluble in water and poorly soluble in organic solvents; and ii) DS above 1.1 are insoluble in water and soluble in organic solvents, which drastically reduces their hydration and gel formation (Colussi et al., 2015).

There are work in the literature studying the degree of substitution of starch from several sources, such as corn starch (Sweedman et al., 2013), yam starch (Yu et al., 2014) and ginger starch (Zhang et al.,2009) and rice starch (Bartz et al., 2012). However, there is a lack of study of how different degrees of substitution interfere with mechanical, structural and hydrophobic properties of starch acetate films.

${ }^{1}$ Faculdade de Química e Engenharia de Alimentos, Universidade Federal de Uberlândia - UFU, Uberlândia, MG, Brasil

${ }^{2}$ Departamento de Química e Engenharia de Alimentos, Universidade Federal de Santa Catarina - UFSC, Florianópolis, SC, Brasil

${ }^{*}$ Corresponding author: vivianfeq@ufu.br 
In this context, films prepared with low degrees of substitution starch acetates in water are an interesting alternative for the preparation of less hygroscopic biodegradable materials. Thus, the objective of this work was to develop films from cassava starch modified by acetylation with low degrees of substitution, using acetic anhydride as the esterification reagent, water as the solvent of film-forming solutions, with two glycerol concentrations as plasticizer ( $0.25 \mathrm{~g} .100 \mathrm{~g}^{-1}$ starch and $0.30 \mathrm{~g} .100 \mathrm{~g}^{-1}$ starch) and conditioned at humidity relative of $75 \%$ and 96 hours. FTIR, mechanical properties, solubility in water and microstructural analysis were performed to compare films based on native starch and on acetylated starches.

\section{Experimental and/or theoretical methods}

\subsection{Materials}

The synthesis of cassava starch acetate (CSA) was partially based on the method proposed by Feuer (1998) and modified by Larotonda et al. (2003): $75 \mathrm{~g}$ of dry cassava starch (Yoki Alimentos S.A., Paranavaí/PR, Brazil), $135 \mathrm{ml}$ of glacial acetic acid (Synth, Diadema/SP, Brasil) and $138 \mathrm{~mL}$ of acetic anhydride (Synth, Diadema/SP, Brasil) were placed in a $1000 \mathrm{~mL}$ beaker on magnetic stirrer-heating plate. After reaching the temperature of $40^{\circ} \mathrm{C}$, the mixture was removed from the heating source and a catalyst mixture was carefully added $(1.05 \mathrm{~mL}$ of concentrated sulfuric acid (Synth, Diadema/SP, Brasil) and $12.45 \mathrm{~mL}$ of glacial acetic acid). The reactive mixture was maintained, under stirring, at the reaction temperatures of $20^{\circ} \mathrm{C}$ and $47^{\circ} \mathrm{C}$ (S - native starch; $\mathrm{S}_{0.6}$ - starch acetate - 0.6 DS; $\mathrm{S}_{1.1}$ - starch acetate - 1.1 DS) for 2 hours. When the reaction was completed, $250 \mathrm{~mL}$ of distilled water at $5{ }^{\circ} \mathrm{C}$ was added to the mixture to precipitate the starch acetate and the supernatant was removed and discarded. The precipitate was washed with distilled water, filtered and dried in a forced air oven (Tecnal, TE 394/2, Piracicaba, Brazil) for 8 hours at $60^{\circ} \mathrm{C}$.

The degree of substitution (DS) of the cassava starch acetate was determined by $\mathrm{HCl}$ titration, according to Wurzburg (1964). The acetyl content (\%Acetyl) was calculated as follows (Equation 1):

$\%$ Acetyl $=\frac{\left[\left(V_{B}-V_{S}\right) \times \mathrm{M} \times 43\right]}{\mathrm{m}} \times 100$

in which, $V_{B}$ is the $\mathrm{HCl}$ volume (mL) used to titrate the blank sample, $V_{S}$ is the $\mathrm{HCl}$ volume $(\mathrm{mL})$ used to titrate the starch acetate sample, $M$ is the concentration of the $\mathrm{HCl}\left(\mathrm{mol}_{\mathrm{L}} \mathrm{L}^{-1}\right), 43$ is the molar mass of the acetyl group $\left(\mathrm{g} \cdot \mathrm{mol}^{-1}\right)$, and $m$ is the mass (g) of the starch acetate (Whistler \& Daniel, 1995).

The degree of substitution was calculated according to the Equation 2.

$$
\mathrm{DS}=\frac{(162 \times \% \text { Acetyl })}{43 \times 100-((43-1) \times \% \text { Acetyl })}
$$

$\mathrm{M}=$ sample amount as dry substance (g), 43 = the molar mass of the acetyl group $\left(\mathrm{g} \cdot \mathrm{mol}^{-1}\right), 162=$ molecular weight of the anhydroglucose unit, $1=$ the hydrogen mass.

\subsection{Apparent viscosity}

The rheological behavior of the film forming suspensions $\mathrm{S}, \mathrm{S}_{0.6}$ and $\mathrm{S}_{1.1}$ without glycerol was performed in a Haake rotational viscometer with concentric cylinders (VT550, Haake, Germany), using a controlled temperature system set at $30^{\circ} \mathrm{C}$. The resulting curves were plotted as shear stress $(\tau)$ versus shear rate $(\gamma)$, and modeled using the Ostwald de Waele equation for fluid (Equation 3):

$$
\tau=k^{n}
$$

in which $k$ is the consistency coefficient and $n$ is the flow behavior index.

\subsection{Intrinsic viscosity}

Starch solutions with concentrations of $0.2,0.3,0.4,0.5,0.6$ and $0.7 \mathrm{~g}$ starch. $\mathrm{mL}^{-1}$ solution were prepared in $1 \mathrm{~mol} . \mathrm{L}^{-1} \mathrm{KOH}$ solution and the intrinsic viscosity was analyzed according to Leach \& Schoch (1963). To determine the flow times of the solvent ( $\mathrm{KOH}$ solution) and of the starch solutions, $10 \mathrm{~mL}$ of solution were transferred to an Ostwald capillary viscometer (AVS 350, CT 53, Schott, Mainz Germany) at $30^{\circ} \mathrm{C}$. The flow time of 1 mol. $\mathrm{L}^{-1} \mathrm{KOH}$ solution was used as the reference flow ( $\mathrm{T}_{\mathrm{o}}$ - time zero) and the relative viscosity was obtained from the ratio $T / T_{0}$, in which $T$ is the flow time (s) of the tested concentration. The specific viscosity $\left(\eta_{\text {esp }}\right)$ was given by $\eta_{\text {esp }}-1$ and the reduced viscosity $\left(\eta_{\text {red }}\right)$ by $\eta_{\text {esp }} / \mathrm{C}$ (in which $C$ is the starch concentration). The intrinsic viscosity $(\eta)$ was determined by the extrapolation to zero of the straight line obtained from the linear fit of the experimental data of reduced viscosity as a function of concentration. The ratio of intrinsic viscosity to the molar mass $(M)$ was given by the Staudinger-Mark-Houwink equation (Equation 4), where $K\left(1.18 \times 10^{-3}\right)$ and $\alpha(0.89)$ are empirical parameters (Whistler \& Daniel, 1995).

$[\eta]=K \cdot M^{\alpha}$

\subsection{Starch films preparation}

Filmogenic suspensions were prepared in triplicate with native starch $(S)$ and acetylated starches with two different DS $\left(\mathrm{S}_{0.6}\right.$ and $\left.\mathrm{S}_{1.1}\right)$ obtained as described above. Film-forming suspensions were prepared by suspending $3 \mathrm{~g} .100 \mathrm{~g} \mathrm{~g}^{-1}$ of starch or starch acetate in distilled water and glycerol was added at the concentration of $25 \mathrm{~g} .100 \mathrm{~g}^{-1}\left(\mathrm{~S} 25, \mathrm{~S}_{0.6} 25\right.$ and $\left.\mathrm{S}_{1.1} 25\right)$ or $30 \mathrm{~g} .100 \mathrm{~g}^{-1}$ ( $\mathrm{S} 30, \mathrm{~S}_{0.6} 30$ and $\mathrm{S}_{1.1} 30$ ) of the total dry matter. The suspensions were heated up to $85^{\circ} \mathrm{C}$, under stirring, for 30 minutes to dissolve a greater part of the starch acetate granules in water. Film-forming suspensions were cast in acrylic plates and dried in a forced air oven at $35^{\circ} \mathrm{C}$ for 7 hours. Before further analyses, all produced films ( $\mathrm{S} 25, \mathrm{~S}_{0.6} 25, \mathrm{~S}_{1.1} 25, \mathrm{~S} 30, \mathrm{~S}_{0.6} 30$ and $\mathrm{S}_{1.1} 30$ ) were conditioned at two different relative humidity ( $58 \%$ and $75 \% \mathrm{RH}$ ) for 96 hours.

\subsection{Microstructure analysis}

A scanning electron microscopy (JSM 6390LV, JEOL, Japan) was used to evaluate the effect of acetylation on starch granules $\left(\mathrm{S}, \mathrm{S}_{0.6}\right.$ and $\left.\mathrm{S}_{1.1}\right)$ and the surface and cross section of 
film samples (S25, $\mathrm{S}_{0.6} 25$ and $\left.\mathrm{S}_{1.1} 25\right)$. Samples were mounted on aluminum planchets, coated with gold in an anion-sputtering apparatus (Leica EM 500 SCD, Leica Microsystems, Germany) and scanning electron micrographs were obtained with a tungsten electron source, secondary electron detector and backscattered operating at $10 \mathrm{kV}$.

\subsection{Fourier transformed IR spectroscopy (FTIR)}

As the glycerol bands did not show differences in the spectra, so only a concentration of starch was selected, the film with better mechanical properties. $S, \mathrm{~S}_{0.6}$ and $\mathrm{S}_{1.1}$ starch granules and S25, $S_{0.6} 25$ and $S_{1.1} 25$ films infrared spectra between $400 \mathrm{~cm}^{-1}$ and $4000 \mathrm{~cm}^{-1}$ were recorded using a FTIR spectrophotometer (FTLA 2000, ABB, Zurich) (Bartz et al., 2012). Tablets were prepared by mixing the starch samples with $\mathrm{KBr}$ with a ratio of 1:100 (sample weight: $\mathrm{KBr}$ weight). Approximately $1.0 \mathrm{mg}$ of the samples was dried in a vacuum oven for 15 hours at $60^{\circ} \mathrm{C}$. After this period, $100 \mathrm{mg}$ of $\mathrm{KBr}$ were added and the mixture homogenized in agate mortar. The pellets were prepared and left in a vacuum oven at $110^{\circ} \mathrm{C}$ for 20 hours. Ten readings were performed for each sample at a resolution of $4 \mathrm{~cm}^{-1}$.

\subsection{Films structure analyses}

The thickness of the films was measured using a digital micrometer (Digimatic, Mitutoyo Co., Japan), averaging the values determined on 6 to 8 locations randomly chosen for each sample. The moisture content was determined at least in triplicate by the gravimetric method at $105^{\circ} \mathrm{C}$ for 24 hours. Moisture content was expressed as a percentage of total weight (wet basis). The samples were conditioned in saturated saline solutions of sodium bromide and sodium chloride at $58 \%$ and $75 \%$ relative humidity, respectively, at $25^{\circ} \mathrm{C}$ for 96 hours prior to analysis. Tensile tests were run with 15 samples for each analyze using a texture analyzer (TA-XT2i Stable Micro System, Surrey, UK) according to the ASTM D828-97 standard test methods (American Society for Testing and Materials, 1997). The samples for the tensile test were cut in dimensions of $25.4 \mathrm{~mm}$ by $100 \mathrm{~mm}$ and adjusted to the claws of the equipment, whose initial distance was $100 \mathrm{~mm}$. The tensile velocity was $0.8 \mathrm{~mm} \cdot \mathrm{s}^{-1}$.

Water vapor permeability (WVP) was determined at least in triplicate following the gravimetric method based on the ASTME96-00 standard methodology (American Society for Testing and Materials, 2000).

Water solubility (WS) determination was assessed in three circular samples $(\phi=2 \mathrm{~cm})$ of each film ( $225, \mathrm{~S}_{0.6} 25, \mathrm{~S}_{1.1} 25$, S30, $\mathrm{S}_{0.6} 30$ and $\mathrm{S}_{1.1} 30$ ). Samples were dried for 24 hours in a desiccators containing silica gel at room temperature. Then, samples were weighed and immersed in $50 \mathrm{~mL}$ of distilled water containing sodium azide $\left(0.02\right.$ g. $\left.100 \mathrm{~mL}^{-1}\right)$ for 24 hours without agitation. The insolubilized sample was determined by filtration and drying at $105^{\circ} \mathrm{C}$. Film solubility, FS (\%) was calculated using the expression 5.in which, $W_{o}$ is the initial weight of the film expressed as dry matter and $W_{f}^{o}$ is the weight of the insolubilized desiccated film residue. All tests were performed in triplicate.

$\left[\left(W_{o}-W_{f}\right) / W_{o}\right] \times 100$
Moisture sorption isotherms of films ( $\mathrm{S} 25, \mathrm{~S}_{0.6} 25, \mathrm{~S}_{1.1} 25, \mathrm{~S} 30, \mathrm{~S}_{0.6} 30$ and $S_{1.1} 30$ ) were obtained by the gravimetric/static method. Samples were conditioned for 7 days in desiccators with silica gel at $25^{\circ} \mathrm{C}$. Then, $0.500 \pm 0.001 \mathrm{~g}$ of each sample was placed at different relative humidifies (from $7 \%$ to $90 \%$ ) obtained by appropriate saturated saline solutions at $25^{\circ} \mathrm{C}$. Samples were periodically weighed until constant weight ( $\approx 14$ days) then moisture content was determined. The Guggenheim-Anderson-de-Boer (GAB) model (Equation 6) was fitted to the experimental results and model parameters were determined by non-linear regression, using the software Statistica 6.0 (Statsoft Inc., Tulsa, USA).

$$
X_{w}=\frac{\left(C k m_{0} a_{w}\right)}{\left(1-k a_{w}\right)\left(1-k a_{w}+C k a_{w}\right)}
$$

in which, $X_{w}$ is the equilibrium moisture (g.g ${ }^{-1}$ water: dry mass), $a_{w}$ is the water activity, $m_{0}$ is the monolayer water content, $k$ the sorption heat of the multilayer, and $C$ is the Guggenheim constant, which represents the sorption heat of the first layer.

\subsection{Statistical analysis}

The results were evaluated by one-way ANOVA at the 95\% probability level. In the case of significant effects $(p \leq 0.05)$, the means were compared using the Tukey's test. These analyses were performed using the software Statistica 6.0 (Statsoft Inc., Tulsa, USA).

\section{Results}

\subsection{Obtaining starch acetate}

The degree of substitution resulted from the reaction temperatures of $20^{\circ} \mathrm{C}\left(\mathrm{S}_{0.6}\right)$ was of $0.6 \mathrm{DS}$, while $1.1 \mathrm{DS}\left(\mathrm{S}_{1.1}\right)$ was observed at $47^{\circ} \mathrm{C}$, confirming that higher reaction temperatures results in higher degrees of substitution (Larotonda et al., 2003; Lepeniotis \& Feuer, 1997). Moreover, at temperatures higher than $47^{\circ} \mathrm{C}$, films showed regions in which the acetate was insoluble (data not shown). This lower solubility of acetylated starch can be attributed to the introduction of bulky acetyl groups in the starch molecules, which impart greater hydrophobicity than the hydroxyl groups in the starch molecule (Colussi et al., 2015; Sweedman et al., 2013).

A significant decrease of approximately $64 \%$ of the intrinsic viscosity was observed in acetylated starch $\left(\mathrm{S}_{0.6}\right.$ and $\left.\mathrm{S}_{1.1}\right)$ in comparison to the native starch $(S)$. The intrinsic viscosities of the starch acetates were $4.20 \pm 0.10 \mathrm{~mL}^{-1} \mathrm{~g}^{-1}$ for $\mathrm{S}_{0.6} 3.30 \pm 0.08 \mathrm{~mL} . \mathrm{g}^{-1}$ for $\mathrm{S}_{1.1}$ and $153.88 \pm 3.63 \mathrm{~mL} . \mathrm{g}^{-1}$ for $\mathrm{S}$. The lower values of starch acetate might indicate that starch hydrolysis not only affected the surface of the granule, but also the rest of the starch structure (Yu et al., 2014). Zambrano et al. (2001) observed reduction from 258 to $22 \mathrm{~mL} . \mathrm{g}^{-1}$ of intrinsic viscosity when starch acetylating was performed.

Figure 1 shows the flow curves obtained from film forming suspensions $\mathrm{S}, \mathrm{S}_{0.6}$ and $\mathrm{S}_{1.1}$, without glycerol (to avoid interferences on the apparent viscosity in the acetate starch). Both starch acetate and native starch suspensions showed Non-Newtonian behavior, characterized by a decrease in viscosity with increasing 


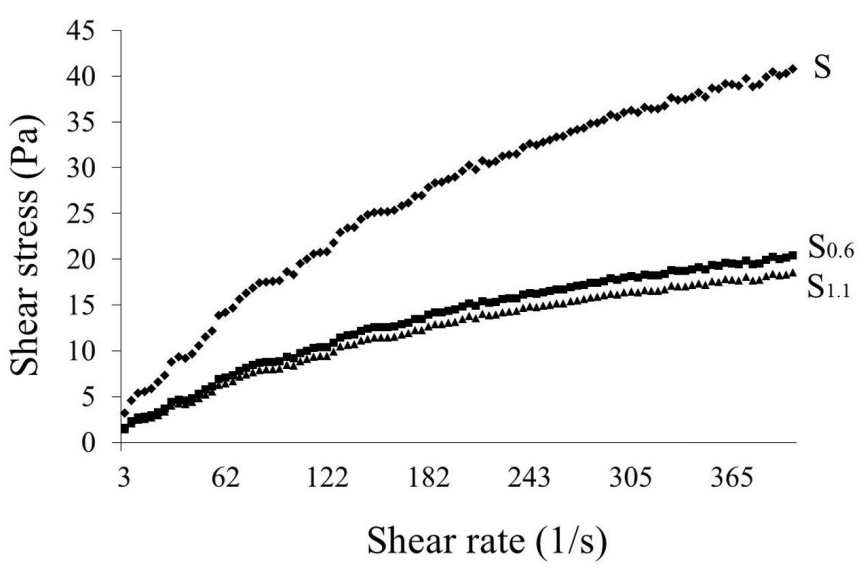

Figure 1. Rheological flow curves of $S, S_{0.6}$ and $S_{1.1}$ film forming suspensions at increasing shear rates $\left(\mathrm{s}^{-1}\right)$. strain. The same behavior was observed by López et al. (2008) for filmogenic corn starch and corn starch acetate suspensions. Flow curves of starch acetate suspensions showed lower values of shear stress than those of the native one. The apparent viscosities obtained were 87.422 .56 m.Pa.s for S, and $60.23 \pm 2.32$ for $\mathrm{S}_{0.6}$ and $58.21 \pm 2.99 \mathrm{~m}$.Pa.s for $\mathrm{S}_{1.1}$. Thus, the increasing DS result in a reduction of the shear stress. Saartrat et al. (2005) found that the viscosities of acetylated starches with high degrees of substitution were lower than those of native starches. Bartz et al. (2012) found starch acetate rice with 0.01 DS presented a viscosity reduction of $11.5 \%$ and acetate 0.67 DS of $49 \%$. The reduction in the paste viscosity may be attributed to the depolymerization of the starch chains during acetylation.

Scanning electron microscopy was performed to observe the effect caused by acetylation on the starch granules, as shown in Figure 2. A slight variation in the granule size and shape of
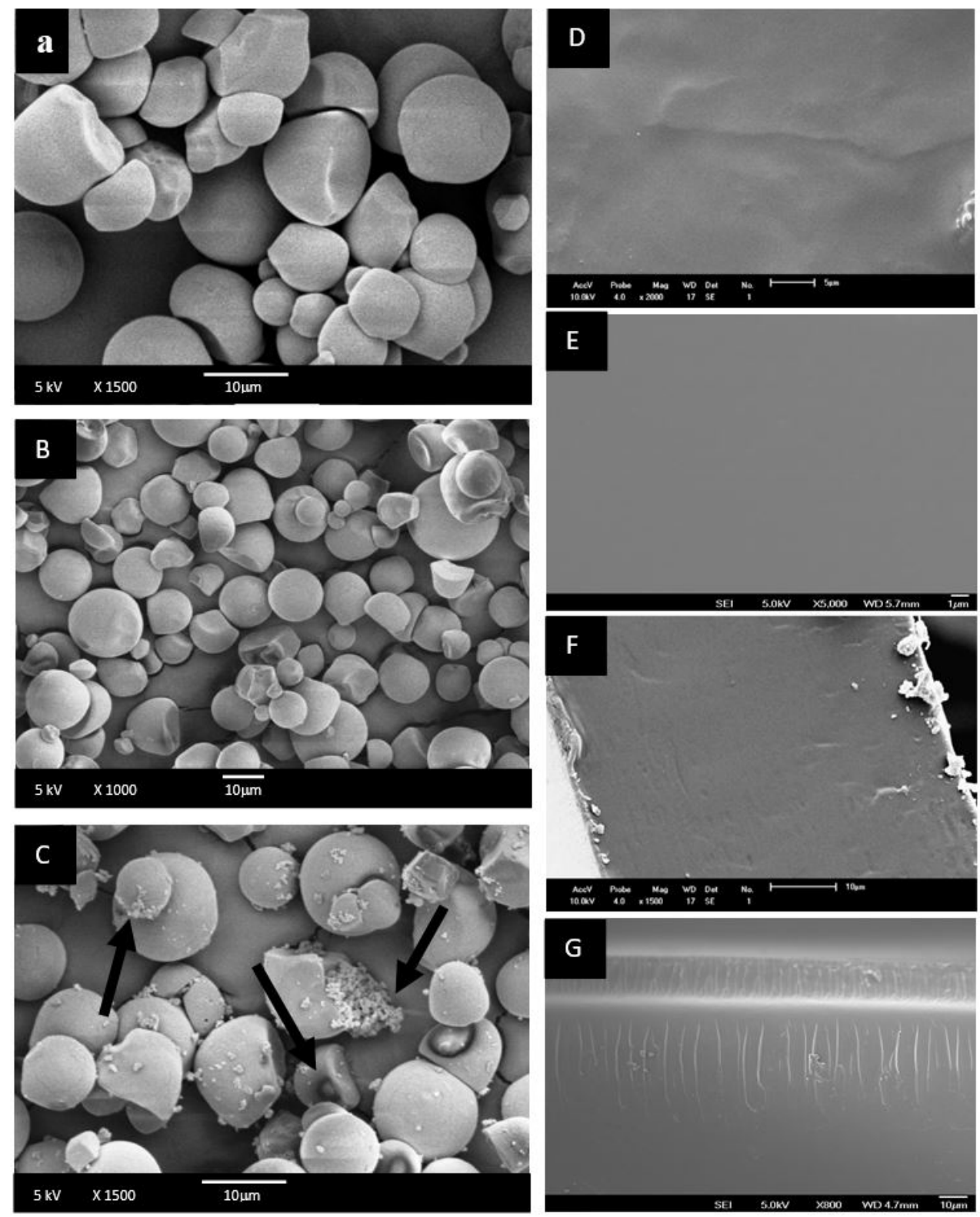

Figure 2. Scanning electron microscopy images of the native starch $S(A)$, acetylated $S_{0.6}(B)$ and $S_{1.1}(C)$ granules. The surfaces of native starch, S25 (D) starch acetate films, $S_{0.6} 25$ (E), and the cross sections of native starch, S25 (F) and starch acetate films, $S_{0.6} 25(\mathrm{G})$. 
$\mathrm{S}_{0.6}$ (Figure 2b) was observed in comparison with S (Figure 2a). Higher acetylation temperature $\left(\mathrm{S}_{1.1}\right)$ there was an increasing destruction degree on the surface of the starch granules (Figure 2c). This observation also corroborates previous investigations on corn starch (Sweedman et al., 2013), yam starch (Yu et al., 2014) and ginger starch (Zhang et al., 2009). Sha et al. (2012) explained that the destruction of the granules after acetylation can be attributed to the increase in the intensity of acetylation that damage the hydrogen intermolecular bonds and promote the disruption of some starch granules. Bello-Pérez et al. (2010) and Singh et al. (2007) also reported fusion of potato starch granules with DS higher than 1.78.

Fourier transform infrared spectra of $S, S_{0.6}$ and $S_{1.1}$ starch granules (Figure 3a) and S25, $\mathrm{S}_{0.6} 25$, and $\mathrm{S}_{1.1} 25$ films (Figure $3 \mathrm{~b}$ ) were performed to assess the chemically modifications of the acetylation reaction. According with Hong et al. (2015) the spectra of the starch acetate are characterized by three bands, i.e. i) the band at $1750 \mathrm{~cm}^{-1}$ assigned to the group $\mathrm{C}=\mathrm{O}$; ii) the band $1375 \mathrm{~cm}^{-1}$ assigned to the group $\mathrm{CH}_{3}$ and iii) the band $1240 \mathrm{~cm}^{-1}$ assigned to the group $\mathrm{C}-\mathrm{O}$.

The band absorption at $1750 \mathrm{~cm}^{-1}$ is commonly related with the ester carbonyl group $\mathrm{C}=\mathrm{O}$, which has been associated to the acetylation reaction (Bello-Pérez et al., 2010; Chi et al., 2008; Larotonda et al., 2004). The spectra of $S$ and $S_{0.6}$ granules (Figure 3a) did not presented as much differences as compared with $S_{1.1}$. However, $S_{1.1}$ showed a slight deformation at the location the band at $1743 \mathrm{~cm}^{-1}$, as indicated by the black arrows in Figure 3a. Similar results were observed by Bartz et al. (2012), which evaluated pasting properties of native and acetylated rice starches and observed the appearance of peak at $1743 \mathrm{~cm}^{-1}$ band with increasing degree of substitution.
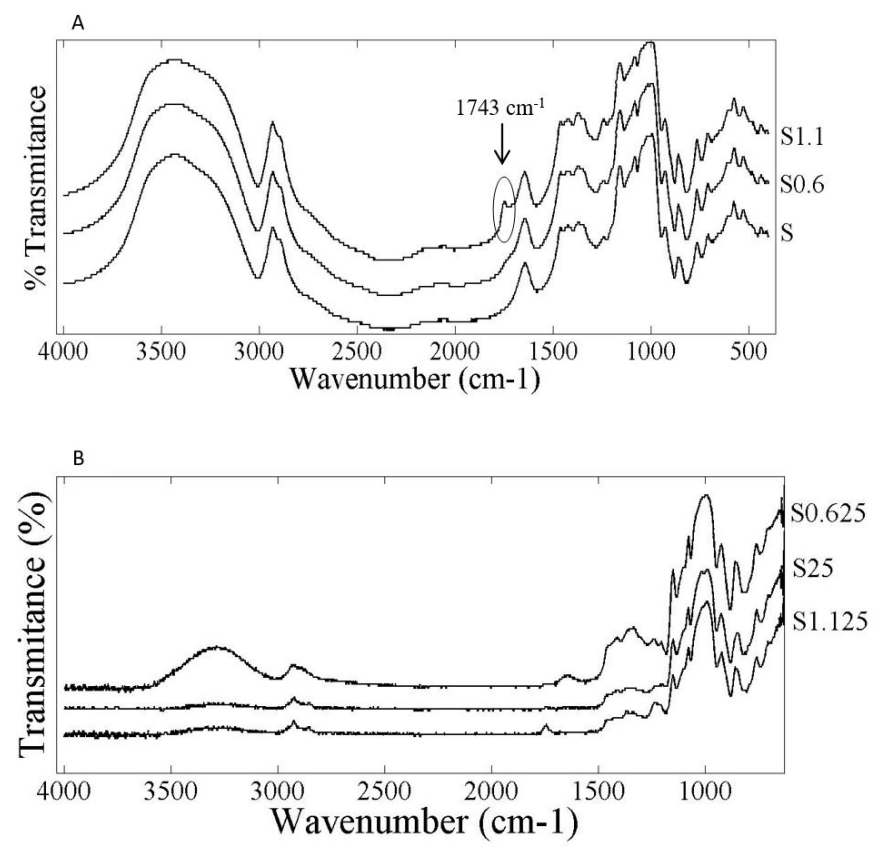

Figure 3. FTIR spectra of $S, S_{0.6}$ and $S_{1.1}$ starch granules (a) and S25, $\mathrm{S}_{0.6} 25$ and $\mathrm{S}_{1.1} 25$ films (b).
Larotonda et al. (2004) reported similar result. The spectra presented by these authors show that, with the increasing reaction temperature (higher degree of substitution), the intensity of the bands $1370 \mathrm{~cm}^{-1}, 1242 \mathrm{~cm}^{-1}$ and $990 \mathrm{~cm}^{-1}$ increased. Chi et al. (2008) reported that the FTIR spectra of the granule acetylated corn starches with different DS $(0.85,1.78$ and 2.89) showed new absorption bands at $1754 \mathrm{~cm}^{-1}$ (carbonyl $\mathrm{C}=\mathrm{O}$ ), $1435 \mathrm{~cm}^{-1}$ (asymmetric $\mathrm{CH}_{3}$ deformation vibration), $1375 \mathrm{~cm}^{-1}\left(\mathrm{CH}_{3}\right.$ symmetric deformation vibration), and $1240 \mathrm{~cm}^{-1}$ (CO stretching vibrational). The absorption bands observed for the acetylated starches indicated that the reaction products were formed during the esterification process.

\subsection{Films analyses}

Films with glycerol concentration of $25 \mathrm{~g} \cdot 100 \mathrm{~g}^{-1}\left(\mathrm{~S} 25, \mathrm{~S}_{0.6} 25\right.$ and $\left.\mathrm{S}_{1.1} 25\right)$ and $30 \mathrm{~g} .100 \mathrm{~g}^{-1}\left(\mathrm{~S} 30, \mathrm{~S}_{0.6} 30\right.$ and $\left.\mathrm{S}_{1.1} 30\right)$ were easy to handle and exhibited a homogeneous, transparent, bright appearance and an average thickness of $95 \pm 8 \mu \mathrm{m}$.

\section{Mechanical properties}

The results of tensile strength (TS), elongation at break ( $\varepsilon$ ) and Young's modulus (Y) of the starch and starch acetate films $\left(\mathrm{S} 25, \mathrm{~S}_{0.6} 25, \mathrm{~S}_{1.1} 25, \mathrm{~S} 30, \mathrm{~S}_{0.6} 30\right.$ and $\left.\mathrm{S}_{1.1} 30\right)$, conditioned at the relative humidity of $58 \%$ and $75 \%$ for 96 hours are presented in Table 1.

Acetate films conditioned at 58\% RH presented higher values of the tensile strength (TS) than films conditioned at $75 \% \mathrm{RH}$, which is similar to results reported by the literature for starch-based films (Müller et al., 2009; Martelli et al., 2006; Mali et al., 2005). However, the films conditioned of 58\% RH showed values of the elongation at break slightly higher when compared to the films conditioned at $75 \% \mathrm{RH}$. The values of the tensile strength of starch acetate films were $1.5\left(\mathrm{~S}_{0.6}\right)$ and $2\left(\mathrm{~S}_{1.1}\right)$ times higher than $\mathrm{S}$ films. This behavior can be explained by

Table 1. Tensile strength(TS), elongation at break $(\varepsilon)$ and Young's modulus $(\mathrm{Y})$ of the $\mathrm{S}, \mathrm{S}_{0.6}$ and $\mathrm{S}_{1.1}$ films with different concentration of glycerol (25g. $100 \mathrm{~g}^{-1}$ and $30 \mathrm{~g} .100 \mathrm{~g}^{-1}$ ) and e conditioned at $58 \%$ and $75 \% \mathrm{RH}$.

\begin{tabular}{cccc}
\hline Samples & TS (MPa) & $\varepsilon(\%)$ & $\Upsilon(\mathrm{MPa} / \%)$ \\
\hline \multicolumn{4}{c}{$58 \% \mathrm{RH}$} \\
\hline $\mathrm{S} 25$ & $4.30 \pm 0.27^{\mathrm{a} / \mathrm{x}}$ & $50.33 \pm 2.24^{\mathrm{a} / \mathrm{x}}$ & $1.72 \pm 0.32^{\mathrm{a} / \mathrm{x}}$ \\
$\mathrm{S}_{0.6} 25$ & $8.42 \pm 0.84^{\mathrm{b} / \mathrm{x}}$ & $16.11 \pm 0.91^{\mathrm{b} / \mathrm{x}}$ & $2.50 \pm 0.45^{\mathrm{a} / \mathrm{x}}$ \\
$\mathrm{S}_{1.1} 25$ & $6.57 \pm 0.28^{\mathrm{c} / \mathrm{x}}$ & $19.78 \pm 1.96^{\mathrm{c} / \mathrm{x}}$ & $2.19 \pm 0.57^{\mathrm{a} / \mathrm{x}}$ \\
$\mathrm{S}_{0}$ & $3.36 \pm 0.29^{\mathrm{d} / \mathrm{x}}$ & $95.05 \pm 13.6^{\mathrm{d} / \mathrm{x}}$ & $0.53 \pm 0.14^{\mathrm{b} / \mathrm{x}}$ \\
$\mathrm{S}_{0.6} 30$ & $6.25 \pm 0.35^{\mathrm{c} / \mathrm{x}}$ & $30.17 \pm 1.86^{\mathrm{e} / \mathrm{x}}$ & $1.15 \pm 0.21^{\mathrm{c} / \mathrm{x}}$ \\
$\mathrm{S}_{1.1} 30$ & $5.04 \pm 0.32^{\mathrm{e} / \mathrm{x}}$ & $30.27 \pm 1.33^{\mathrm{e} / \mathrm{x}}$ & $1.09 \pm 0.05^{\mathrm{c} / \mathrm{x}}$ \\
\hline \multicolumn{4}{c}{$75 \% \mathrm{RH}$} \\
\hline $\mathrm{S}_{5 .} 25$ & $3.89 \pm 0.29^{\mathrm{a} / \mathrm{x}}$ & $55.96 \pm 2.02^{\mathrm{a} / \mathrm{y}}$ & $0.89 \pm 0.08^{\mathrm{a} / \mathrm{y}}$ \\
$\mathrm{S}_{0.6} 25$ & $6.93 \pm 0.55^{\mathrm{b} / \mathrm{y}}$ & $20.78 \pm 0.88^{\mathrm{b} / \mathrm{y}}$ & $1.37 \pm 0.23^{\mathrm{b} / \mathrm{y}}$ \\
$\mathrm{S}_{1.1} 25$ & $4.91 \pm 0.29^{\mathrm{c} / \mathrm{y}}$ & $24.05 \pm 1.42^{\mathrm{c} / \mathrm{y}}$ & $0.43 \pm 0.09^{\mathrm{c} / \mathrm{y}}$ \\
$\mathrm{S}_{30}$ & $2.43 \pm 0.34^{\mathrm{d} / \mathrm{y}}$ & $105.0 \pm 12.7^{\mathrm{d} / \mathrm{x}}$ & $1.09 \pm 0.13^{\mathrm{ab} / \mathrm{y}}$ \\
$\mathrm{S}_{0.6} 30$ & $4.66 \pm 0.33^{\mathrm{c} / \mathrm{y}}$ & $33.17 \pm 1.80^{\mathrm{e} / \mathrm{x}}$ & $1.13 \pm 0.19^{\mathrm{ab} / \mathrm{x}}$ \\
$\mathrm{S}_{1.1} 30$ & $3.60 \pm 0.29^{\mathrm{a} / \mathrm{y}}$ & $34.37 \pm 1.43^{\mathrm{e} / \mathrm{y}}$ & $1.23 \pm 0.05^{\mathrm{b} / \mathrm{y}}$ \\
\hline
\end{tabular}

Results are the mean \pm standard deviation. Different letters $(a, b, c)$ in the same column and $\mathrm{RH}$ indicate significant differences among the different film formulation $(\mathrm{P} \leq 0.05)$. Different letters $(\mathrm{x}, \mathrm{y})$ in the same column and sample indicate significant differences among different $\mathrm{RH}(\mathrm{P} \leq 0.05)$. 
the substitution of $\mathrm{OH}^{-}$groups in the starch molecule by acetyl group, making the films more resistant (Ghiotti \& Falcone, 1994; Rosenthal, 1993). As well known, the tensile strength of cassava starch films decreases with increasing low molecular weight plasticizer concentration and relative humidity (Mali et al., 2005).

The elongation at break of $S$ films was 2.5 and 3.0 lower than $\mathrm{S}_{0.6}$ and $\mathrm{S}_{1.1}$ films, respectively. Higher RH (75\%) and glycerol concentration ( $\left.30 \mathrm{~g} .100 \mathrm{~g}^{-1}\right)$ resulted in increased values of elongation at break. Due to the low degree of substitution, there are free hydroxyl groups which are susceptible to binding with water. Replacement of $\mathrm{OH}^{-}$in the starch chains for acetyl groups is a way to decrease the interaction of water and the starch chains. However, the water exerts a plasticizing effect when there is an increase in relative humidity, acting as a potentiality of mobility, its low molecular weight leads to an increase in molecular mobility of amorphous and partially crystalline polymers due of the an increased free volume (Van Der Berg, 1991). These results are in agreement with those reported by several authors about the influence of the plasticizer concentration in hydrophilic films (Müller et al., 2009; Mali et al., 2005;Vicentini et al., 2005; Gontard et al., 1992). López et al. (2008) and Bonacucina et al. (2006) studied the influence of glycerol concentration on the mechanical properties of starch acetate films observing that at higher glycerol concentration the tensile strength decreased and the elongation at break increased. The Young's modulus values $\mathrm{S}_{0.6}$ and $\mathrm{S}_{1.1}$ films conditioned at $58 \% \mathrm{RH}$ were higher than S, but at $75 \% \mathrm{RH}$ the differences between samples were only significant with $25 \mathrm{~g} .100 \mathrm{~g}^{-1}$ of glycerol concentration $(\mathrm{p} \leq 0.05)$. As TS, Y values were reduced by the addition of higher concentration of glycerol.

Independently from the plasticizer concentration, higher DS significantly reduced the TS of the films. This behavior can be related with degree of substitution of acetyl groups, $0.6 \mathrm{DS}$ resulted in higher TS, however higher temperatures of acetylation resulted in a chemical modification that conferred lower availability for the matrix linkage, influencing negatively the film mechanical resistance. At lower glycerol concentrations, higher degree of substitution resulted in slightly higher film elongation, which could be related to a less efficient starch gelatinization due to the higher acetylation.

\section{Water barrier properties}

Moisture contents, water solubility's and water vapor permeability's of starch and starch acetate films $\left(\mathrm{S} 25, \mathrm{~S}_{0.6} 25, \mathrm{~S}_{1.1} 25\right.$, S30, $S_{0.6} 30$ and $S_{1.1} 30$ ) are shown in Table 2 . The water solubility was reduced from $25 \%$ for $\mathrm{S}$ to $20 \%$ for $\mathrm{S}_{0.6}$ and to $22 \%$ for $\mathrm{S}_{1.1}$ films. This reduction can be attributed the modification reaction, making the starch less hygroscopic (Sweedman et al., 2013).

Because of the glycerol hydrophilic nature, a higher amount of this plasticizer increased the water solubility of the films (Sothornvit \& Krochta, 2001; Cova et al., 2010). López et al. (2008) also reported values of $19 \pm 3.48 \mathrm{~g} .100 \mathrm{~g}^{-1}$ starch and $25 \pm 4.46 \mathrm{~g}^{2} 100 \mathrm{~g}^{-1}$ starch for the water solubility of corn starch acetate films with glycerol concentrations of $2.5 \mathrm{~g} .100 \mathrm{~g}^{-1} \mathrm{starch}$ and $3.25 \mathrm{~g} .100 \mathrm{~g}^{-1}$ starch, respectively.
The DS and the glycerol concentration did not significantly affect the water vapor permeability $(\mathrm{P} \leq 0.05)$. However, starch acetate films showed lower values of WVP respect to native starch films. A reduction from about $3.8 \pm 0.27 \times 10^{-7} \mathrm{~g} \cdot \mathrm{m} / \mathrm{m}^{2} . h . P a$ to about $2.35 \pm 0.21 \times 10^{-7} \mathrm{~g} . \mathrm{m} / \mathrm{m}^{2}$.h.Pa was observed when $\mathrm{S}_{0.6}$ and $\mathrm{S}_{1.1}$ granules were used to prepare the films instead of $\mathrm{S}$. This reduction can be caused by the substitution of the $\mathrm{OH}$-groups in the starch molecule by acetyl groups, resulting in a less flexible starch structure (Sweedman et al., 2013). The less hygroscopicity of starch acetate also contributed to the lower WVP of starch acetate films.

Figure 4 shows the sorption isotherms of $\mathrm{S} 25, \mathrm{~S}_{0.6} 25$, $S_{1.1} 25, S 30, S_{0.6} 30$ and $S_{1.1} 30$ films. The GAB model was fitted to the experimental data of isotherms. Table 3 shows the model parameters $\left(m_{o}, C\right.$, and $\left.k\right)$ and coefficients of determination $\left(\mathrm{R}^{2}\right)$. The GAB model fitted well the sorption data, as previously reported by other authors for starch based films (Larotonda et al., 2003; Müller et al., 2009; Martelli et al., 2006).

Table 2. Moisture $\left(\mathrm{g} \cdot \mathrm{g}^{-1}\right)$, solubility $\left(\mathrm{g} .100 \mathrm{~g}^{-1}\right)$ and water vapour permeability (g.m $/ \mathrm{m}^{2}$.h.Pa) of the $\mathrm{S}, \mathrm{S}_{0.6}$ and $\mathrm{S}_{1,1}$ films with different concentration of glycerol ( $25 \mathrm{~g} .100 \mathrm{~g}^{-1}$ and $\left.30 \mathrm{~g} .100 \mathrm{~g}^{-1}\right)$.

\begin{tabular}{lccc}
\hline \multicolumn{1}{c}{ Sample } & $\begin{array}{c}\text { Moisture } \\
\left(\mathrm{g} \cdot \mathrm{g}^{-1}\right)\end{array}$ & $\begin{array}{c}\text { Solubility } \\
\left(\mathrm{g} .100 \mathrm{~g}^{-1}\right)\end{array}$ & $\begin{array}{c}\text { WVP } \\
\left(\mathrm{g} \cdot \mathrm{m} / \mathrm{m}^{2} \cdot \mathrm{h} . \mathrm{Pa}\right) \times 10^{-7}\end{array}$ \\
\hline $\mathrm{S} 25$ & $12.45 \pm 0.13^{\mathrm{a}}$ & $25.68 \pm 0.12^{\mathrm{a}}$ & $3.80 \pm 0.27^{\mathrm{a}}$ \\
$\mathrm{S}_{0.6} 25$ & $8.28 \pm 0.10^{\mathrm{b}}$ & $20.31 \pm 0.13^{\mathrm{b}}$ & $2.34 \pm 0.41^{\mathrm{b}}$ \\
$\mathrm{S}_{1.1} 25$ & $8.51 \pm 0.09^{\mathrm{b}}$ & $21.62 \pm 0.13^{\mathrm{b}, \mathrm{c}}$ & $2.54 \pm 0.25^{\mathrm{b}}$ \\
$\mathrm{S}_{0}$ & $12.63 \pm 0.10^{\mathrm{a}}$ & $25.23 \pm 0.11^{\mathrm{a}}$ & $3.77 \pm 0.26^{\mathrm{a}}$ \\
$\mathrm{S}_{0.6} 30$ & $12.64 \pm 0.11^{\mathrm{a}}$ & $20.42 \pm 0.18^{\mathrm{b}}$ & $2.23 \pm 0.26^{\mathrm{b}}$ \\
$\mathrm{S}_{1.1} 30$ & $12.88 \pm 0.12^{\mathrm{a}}$ & $22.27 \pm 0.16^{\mathrm{c}}$ & $2.39 \pm 0.21^{\mathrm{b}}$ \\
\hline
\end{tabular}

Different letters $(\mathrm{a}, \mathrm{b}, \mathrm{c})$ in the same column indicate significant differences among the different film formulation $(\mathrm{P} \leq 0.05)$.
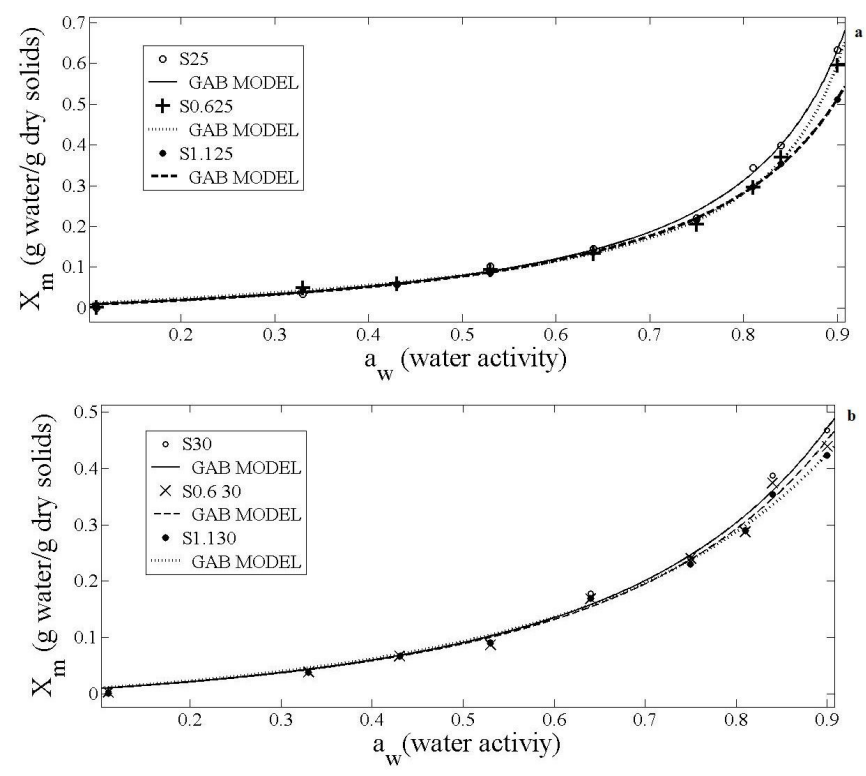

Figure 4. Moisture sorption isotherms of $S 25, S_{0.6} 25$ and $S_{1.1} 25$ (a), S30, $\mathrm{S}_{0.6} 30$ and $\mathrm{S}_{1.1} 30$ (b) films. 
Table 3. Fitting parameters the GAB model for moisture sorption data of $\mathrm{S} 25, \mathrm{~S}_{0.6} 25, \mathrm{~S}_{1.1} 25, \mathrm{~S} 30, \mathrm{~S}_{0.6} 30$ and $\mathrm{S}_{1.1} 30$ films.

\begin{tabular}{lcccc}
\hline & \multicolumn{3}{c}{ Parameters GAB } & \\
\cline { 2 - 4 } & $\begin{array}{c}m_{o} \\
\text { (gwater/gdry } \\
\text { solids) }\end{array}$ & $K$ & $C$ & $\mathrm{R}^{2}$ \\
\hline $\mathrm{S} 25$ & 0.09591 & 0.9691 & 0.793 & $>0.998$ \\
$\mathrm{~S}_{0.6} 25$ & 0.06631 & 0.9965 & 1.525 & $>0.997$ \\
$\mathrm{~S}_{1.1} 25$ & 0.07490 & 0.9303 & 0.758 & $>0.998$ \\
$\mathrm{~S}_{0}$ & 0.07303 & 0.7175 & 1.434 & $>0.999$ \\
$\mathrm{~S}_{0.6} 30$ & 0.06792 & 0.6926 & 1.677 & $>0.997$ \\
$\mathrm{~S}_{01.1} 30$ & 0.06082 & 0.6804 & 1.917 & $>0.998$ \\
\hline
\end{tabular}

No significant differences were found between the sorption isotherms of $\mathrm{S} 25, \mathrm{~S}_{0.6} 25$ and $\mathrm{S}_{1.1} 25$ films $(\mathrm{P} \leq 0.05)$. However, the sorption curves of $S_{0.6} 30$ and $S_{1.1} 30$ films were above those of the S30 films. The moisture equilibrium increased with increasing of the plasticizer content for all the water activity tested.

\section{Films structure}

The micrographs of the $\mathrm{S}_{0.6} 25$ film surface (Figures $2 \mathrm{~d}$ and $2 \mathrm{e}$ ) show that the films prepared with starch acetate were homogeneous and smooth, without fractures or pores. The cross sections of these $\mathrm{S}_{0.6} 25$ films (Figures $2 \mathrm{f}$ and $2 \mathrm{~g}$ ) showed a homogenous but multilayered structure. Thus, the micrographs of the acetate films were similar as the native starch films. López et al. (2008) also reported that corn starch acetate films plasticized with glycerol allowed the production of homogeneous films without pores or cracks. According to Sothornvit \& Krochta (2001), plasticizers interfere in the association of the polymer chain, decreasing the rigidity of the network, producing a less ordered structure.

Figure $3 b$ shows the FTIR spectra obtained in the infrared region for the starch acetate films $\left(\mathrm{S}, \mathrm{S}_{0.6}\right.$ and $\left.\mathrm{S}_{1.1}\right)$ with $25 \mathrm{~g} .100 \mathrm{~g}^{-1}$ glycerol: starch (S25, $\mathrm{S}_{0.6} 25$ and $\left.\mathrm{S}_{1.1} 25\right)$. Film spectra showed the presence of the characteristic bands of the acetate spectra. The band at $3200-3500 \mathrm{~cm}^{-1}$ region, is commonly assigned to the stretching of $-\mathrm{OH}$. S 25 film showed a strong broad band at $3297 \mathrm{~cm}^{-1}$, which was also observed in the spectrum of $S_{1.1} 25$ and S25 films, but with less intensity. A decrease of the intensity of the band at $3000-3500 \mathrm{~cm}^{-1}$ was also reported in the spectra of barley starch with DS of 0.9 and 2.7 (Bello-Pérez et al., 2010), which could be related to lower availability of the hydroxyl groups due to their linkage to the polymer matrix. As granule spectra showed, $\mathrm{S}_{06}$ spectrum suggesting lower solubility of the acetate starch. The region between $2923 \mathrm{~cm}^{-1}$ and $2853 \mathrm{~cm}^{-1}$ has been attributed to the stretching of the $\mathrm{CH}$ bond $\left(\mathrm{CH}_{2}\right.$ symmetrical), representing a new and stronger hydrogen bonds in the films (Larotonda et al., 2004, Marques et al., 2006). The band at $1650 \mathrm{~cm}^{-1}$ is attributed to the bending vibration of $\mathrm{O}-\mathrm{H}$, and at $1743 \mathrm{~cm}^{-1}$ is characteristic of the vibrations of the carbonyl groups. $\mathrm{S}_{0.6} 25$ and $\mathrm{S}_{1.1} 25$ films showed bands at $1645 \mathrm{~cm}^{-1}$ and $1743 \mathrm{~cm}^{-1}$ respectively, while S25 did not present any band in that region (Bartz et al., 2012). The introduction of the acetyl group into the starch molecule has been associated with the presence of a band around $1650 \mathrm{~cm}^{-1}$ and $1740 \mathrm{~cm}^{-1}$ for low and high DS, respectively (Bello-Pérez et al., 2010).
The absorption band at $1450 \mathrm{~cm}^{-1}$ is attributed to the angular deformation of the $\mathrm{C}-\mathrm{H}$ bond and glycerol exhibited a characteristic peak at $1456 \mathrm{~cm}^{-1}$ as was indicated by Zhang \& Han (2006), however this band was not observed in plasticized films. The band at $1369-1370 \mathrm{~cm}^{-1}$ is assigned to the deformation vibration of the symmetrical $\mathrm{CH}_{3}$, and the band at $1241 \mathrm{~cm}^{-1}$ corresponds to the stretching vibrational of $\mathrm{C}-\mathrm{O}$. These band in the films $\mathrm{S} 25, \mathrm{~S}_{0.6} 25$ and $\mathrm{S}_{1.1} 25$ showed increased intensity, while the highest DS (1.1) showed the highest peak, which suggest that products of the acetylation reaction were formed during the esterification process (Chi et al., 2008).

In the region between $1200 \mathrm{~cm}^{-1}$ and $900 \mathrm{~cm}^{-1}$, the bands are associated with vibrations of the $\mathrm{C}-\mathrm{O}, \mathrm{C}-\mathrm{C}$ and $\mathrm{C}-\mathrm{O}-\mathrm{H}$ bonds (Marques et al., 2006). The band at $990 \mathrm{~cm}^{-1}$, which is mainly due to the vibrations of $\mathrm{C}-\mathrm{O}-\mathrm{H}$, is sensitive to the water content in the intra molecular hydrogen bond. Changes in these bands could be associated with vibrations of the $\mathrm{C}-\mathrm{O}-\mathrm{H}$ bond, hydration with water or changes from an amorphous state to a semi-crystalline state (Van Soest et al., 1995). The bands at $1150 \mathrm{~cm}^{-1}$ and $990 \mathrm{~cm}^{-1}$ showed an increased intensity and saturation band for $S_{0.6} 25$ and $S_{1.1} 25$ films compared to S25, according to the arrow in Figure $3 \mathrm{~b}$. This result can be due to new interactions between the glycerol and the resulting acetylated matrix of the polymer.

\section{Conclusions}

Cassava starch acetylation with degree of substitution of 0.6 and 1.1 resulted in films with improved mechanical and water barrier properties. In both cases, acetylation helped to produce films more mechanical resistant, less soluble in water and less permeable to water vapor. 0.6 DS showed better results in general, specially using lower glycerol concentration. Thus, acetylation of starch is an interesting method for the development of starch films with improved properties.

\section{Acknowledgements}

The authors thank the Brazilian research funding agencies CAPES for its financial support of this work.

\section{References}

American Society for Testing and Materials - ASTM. (1997). Annual book of ASTM standards (Designation D 882-97: standard test method for tensile properties of thin plastic sheeting, pp. 159-197). Philadelphia: American Society for Testing and Materials.

American Society for Testing and Materials - ASTM. (2000). Annual book of ASTM standard (Designation E96-00: Standard method for water vapor transmission of materials, pp. 785-792). Philadelphia: American Society for Testing and Materials.

Ashogbon, A. O., \& Akintayo, E. T. (2014). Recent trend in the physical and chemical modification of starches from different botanical sources: a review. Stärke, 66(1-2), 41-57. http://dx.doi.org/10.1002/ star.201300106.

Bartz, J., Madruga, K. M., Klein, B., Pinto, V. Z., \& Dias, Á. R. G. (2012). Pasting properties of native and acetylated rice starches. Brazilian Journal of Food Technology, 15(spe), 78-83. http://dx.doi.org/10.1590/ S1981-67232012005000040. 
Bello-Pérez, L. A., Agama-Acevedo, E., Zamudio-Flores, P. B., MendezMontealvo, G., \& Rodriguez-Ambriz, S. L. (2010). Effect of low and high acetylation degree in the morphological, physicochemical and structural characteristics of barley starch. Lebensmittel-Wissenschaft + Technologie, 43(9), 1434-1440. http://dx.doi.org/10.1016/j. lwt.2010.04.003.

Bonacucina, G., Martino, P. D., Piombetti, M., Colombo, A., Roversi, F., \& Palmieri, G. F. (2006). Effect of plasticizers on properties of pre gelatinized starch acetate (Amprac 01) free films. International Journal of Pharmaceutics, 313(1-2), 72-77. http://dx.doi.org/10.1016/j. ijpharm.2006.01.046. PMid:16540269.

Chi, H., Xu, K., Wu, X., Chen, Q., Xue, D., Song, C., Zhang, W., \& Wang, P. (2008). Effect of acetylation on the properties of corn starch. Food Chemistry, 106(3), 923-928. http://dx.doi.org/10.1016/j. foodchem.2007.07.002.

Colussi, R., El Halal, S. L. M., Pinto, V. Z., Bartz, J., Gutkoski, L. C., Zavareze, E. R., \& Dias, A. R. G. (2015). Acetylation of rice starch in an aqueous medium for use in food. Lebensmittel-Wissenschaft + Technologie, 62(2), 1076-1082. http://dx.doi.org/10.1016/j. lwt.2015.01.053.

Cova, A., Sandoval, A., Balsamo, V., \& Müller, A. J. (2010). The effect of hydrophobic modifications on the adsorption isotherms of cassava starch. Carbohydrate Polymers, 81(3), 660-667. http://dx.doi. org/10.1016/j.carbpol.2010.03.028.

Feuer, L. (1998). Method of making starch acetate using an acid catalyst (U.S. Patent No. US5710269A). Bedminster, New Jersey: CNA Holdings Inc.

Ghiotti, A. M. T., \& Falcone, S. F. (1994). Preparação de acetatos de amido (Nota Técnica DEQI 01/94). Rio de Janeiro: INT.

Golachowski, A., Zięba, T., Kapelko-Żeberska, M., Drożdż, W., Gryszkin, A., \& Grzechac, M. (2015). Current research addressing starch acetylation. Food Chemistry, 176, 350-356. http://dx.doi. org/10.1016/j.foodchem.2014.12.060. PMid:25624243.

Gontard, N., Guilbert, S., \& Cuq, J. L. (1992). Edible wheat gluten films: influence of the main process variables on film properties using response surface methodology. Journal of Food Science, 57(1), 190-199. http://dx.doi.org/10.1111/j.1365-2621.1992.tb05453.x.

Hong, L.-F., Cheng, L., Lee, C. Y., \& Peh, K. K. (2015). Characterisation of physicochemical properties of propionylated corn starch and its application as stabiliser. Food Technology and Biotechnology, 53(3), 278-285. PMid:27904359.

Huang, J., Schols, H., Jin, Z., Sulmann, E., \& Voragen, A. G. J. (2007). Pasting properties and (chemical) fine structure of acetylated yellow pea starch is affected by acetylation reagent type and granule size. Carbohydrate Polymers, 68(3), 397-406. http://dx.doi.org/10.1016/j. carbpol.2006.12.019.

Larotonda, F. D. S., Matsui, K. N., Paes, S. S., \& Laurindo, J. B. (2003). Impregnation of kraft paper with cassava-starch acetate - analysis of the tensile strength, water absorption and water vapor permeability. Stärke, 55(11), 504-510. http://dx.doi.org/10.1002/star.200300179.

Larotonda, F. D. S., Matsui, K. N., Soldi, V., \& Laurindo, J. B. (2004). Biodegradable films made from raw and acetylated cassava starch. Brazilian Archives of Biology and Technology, 47(3), 477-484. http:// dx.doi.org/10.1590/S1516-89132004000300019.

Leach, H. W., \& Schoch, T. J. (1963). Structure of starch granule. II. Action of various amylases on starches. Cereal Chemistry, 38, 318-327.

Lepeniotis, S., \& Feuer, B. I. (1997). Synthesis of starch acetate: statistical designed experiments to optmize the reaction conditions. Chemometrics and Intelligent Laboratory Systems, 36(2), 229-243. http://dx.doi.org/10.1016/S0169-7439(96)00071-8.
López, O. V., Garcia, M. A., \& Zaritzky, N. E. (2008). Film forming capacity of chemically modified corn starches. Carbohydrate Polymers, 73(4), 573-581. http://dx.doi.org/10.1016/j.carbpol.2007.12.023. PMid:26048223.

Mali, S., Sakanaka, L. S., Yamashita, F., \& Grossmann, M. V. E. (2005). Water sorption and mechanical properties of cassava starch films and their relation to plasticizing effect. Carbohydrate Polymers, 60(3), 283-289. http://dx.doi.org/10.1016/j.carbpol.2005.01.003.

Marques, P. T., Lima, A. M. F., Bianco, G., Laurindo, J. B., Borsali, R., Le Meins, J. F., \& Soldi, V. (2006). Thermal properties and stability of cassava starch films cross-linked with tetraethylene glycol diacrylate. Polymer Degradation \& Stability, 91(4), 726-732. http://dx.doi. org/10.1016/j.polymdegradstab.2005.05.020.

Martelli, S. M., Moore, G., Paes, S. S., Gandolfo, C., \& Laurindo, J. B. (2006). Influence of plasticizers on the water sorption isotherms and water vapor permeability of chicken feather keratin films. Lebensmittel-Wissenschaft + Technologie, 39(3), 292-301. http:// dx.doi.org/10.1016/j.lwt.2004.12.014.

Mbougueng, P. D., Tenin, D., Scher, J., \& Tchiégang, C. (2012). Influence of acetylation on physicochemical, functional and thermal properties of potato and cassava starches. Journal of Food Engineering, 108(2), 320-326. http://dx.doi.org/10.1016/j.jfoodeng.2011.08.006.

Müller, C. M. O., Laurindo, J. B., \& Yamashita, F. (2009). Effect of cellulose fibers addition on the mechanical properties and water vapor barrier of starch-based films. Food Hydrocolloids, 23(5), 13281333. http://dx.doi.org/10.1016/j.foodhyd.2008.09.002.

Raina, C. S., Singh, S., Bawa, A. S., \& Saxena, D. C. (2007). A comparative study of Indian rice starches using different modification model solutions. Lebensmittel-Wissenschaft + Technologie, 40(5), 885-892. http://dx.doi.org/10.1016/j.lwt.2006.03.025.

Rosenthal, F. R. T. (1993). Processos de síntese de acetatos de amido, intermediários para poliuretanos (Nota técnica DEQI 02/93). Rio de Janeiro: INT.

Saartrat, S., Puttanlek, C., Rungsardthong, V., \& Uttapap, D. (2005). Paste and gel properties of low-substituted acetylated canna starches. Carbohydrate Polymers, 61(2), 211-221. http://dx.doi.org/10.1016/j. carbpol.2005.05.024.

Sha, X. S., Xiang, Z. J., Bin, L., Jing, L., Bin, Z., Jiao, Y. J., \& Kun, S. R. (2012). Preparation andphysical characteristics of resistant starch (type 4) in acetylated indica rice. Food Chemistry, 134(1), 149-154. http://dx.doi.org/10.1016/j.foodchem.2012.02.081.

Singh, J., Kaur, L., \& Mccarthy, O. J. (2007). Factors influencing the physico-chemical, morphological, thermal and rheological properties of some chemically modified starches for food applications - A review. Food Hydrocolloids, 21(1), 1-22. http://dx.doi.org/10.1016/j. foodhyd.2006.02.006.

Sothornvit, R., \& Krochta, J. M. (2001). Plasticizer effect on mechanical properties of b-lactoglobulin films. Journal of Food Engineering, 50(3), 149-155. http://dx.doi.org/10.1016/S0260-8774(00)00237-5.

Sweedman, M. C., Tizzotti, M. J., Schafer, C., \& Gilbert, R. G. (2013). Structure and physicochemical properties of octenyl succinic anhydride modified starches: A review. Carbohydrate Polymers, 92(1), 905-920. http://dx.doi.org/10.1016/j.carbpol.2012.09.040. PMid:23218383.

Van Der Berg, C. (1991). Food water relationships: Progress and integration, comments and thoughts. In H. Levine \& L. Slade (Eds.), Water relationships in foods (pp. 21-28). New York: Plenum Press. http://dx.doi.org/10.1007/978-1-4899-0664-9_2.

Van Soest, J. J. G., Tournois, H., De Wit, D., \& Vliegenthart, J. F. G. (1995). Short-range structure in (partially) crystalline potato starch 
determinated with attenuated total reflectance Fourier-transform IR spectroscopy. Carbohydrate Research, 279, 201-214. http://dx.doi. org/10.1016/0008-6215(95)00270-7.

Vicentini, N. M., Dupuy, N., Leitzelman, M., Cereda, M. P., \& Sobral, P. J. A. (2005). Prediction of cassava starch edible film properties by chemometric analysis of infrared spectra. Spectroscopy Letters, 38(6), 749-767. http://dx.doi.org/10.1080/00387010500316080.

Whistler, R. L., \& Daniel, J. R. (1995). Carbohydrates. In O. R. Fennema (Ed.), Food chemistry (pp. 69 -137). New York: Marcel Decker.

Wurzburg, O. B. (1964). Acetylation. In R. L. Whistler (Ed.), Methods in carbohydrate chemistry (pp. 286-288). New York: Academic Press.

Yu, S., Xu, J., Zhang, Y., \& Kopparapu, N. K. (2014). Relationship between intrinsic viscosity, thermal, and retrogradation properties of amylose and amylopectin. Czech Journal of Food Sciences, 32(5), 514-520. http://dx.doi.org/10.17221/394/2013-CJFS.

Zambrano, F., Camargo, C. R. O., \& Tavares, D. (2001). Amido de mandioca modificado comparado com substitutos de gordura. Brazilian Journal of Food Technology, 4, 155-161.

Zhang, L., Xie, W., Zhao, X., Liu, Y., \& Gao, W. (2009). Study on the morphology, crystalline structure and thermal properties of yellow ginger starch acetates with different degrees of substitution. Thermochimica Acta, 495(1-2), 57-62. http://dx.doi.org/10.1016/j. tca.2009.05.019.

Zhang, Y., \& Han, J. H. (2006). Plasticization of pea starch films with monosaccharides and polyols. Journal of Food Science, 71(6), 253261. http://dx.doi.org/10.1111/j.1750-3841.2006.00075.x. 